\title{
Implementasi Sensor MQ 4 dan Sensor DHT 22 pada Sistem Kompos Pintar Berbasis IoT (SIKOMPI)
}

\author{
Kevin Diantoro ${ }^{1}$, Reni Rahmadewi ${ }^{2}$, Ibrahim ${ }^{3}$ \\ Jurusan Teknik Elektro Universitas Singaperbangsa Karawang, Karawang \\ Jl. H.S Ronggowaluyo Telukjambe Timur - Karawang 41361 \\ ${ }^{1}$ kevin.diantoro16071@student.unsika.ac.id \\ 2reni.rahmadewi@staff.unsika.ac.id \\ 3ibra. lammada@gmail.com
}

Intisari - Pada proses pengomposan, suhu dan kelembaban harus stabil, tidak boleh terlalu kering atau terlalu lembab agar bakteri dan mikroba pada proses penguraian tidak mati dan dapat bekerja secara optimal. Pada proses pengomposan berlangsung, terjadi pembusukan bahan-bahan yang digunakan yang menghasilkan gas metana. Kadar gas metana yang tinggi berbahaya jika terhirup oleh manusia dan dapat menyebabkan kerusakan pada ozon sehingga menyebabkan efek rumah kaca. Maka dari itu dibuatlah sistem monitoring pada alat pembuatan kompos dengan sistem Internet of Things (IoT) agar pengguna dapat dengan mudah memonitoring kondisi suhu, kelembaban, dan kandungan gas metana yang ada pada kompos saat proses pengomposan berlangsung. Pada penelitian ini menggunakan sensor DHT22 untuk monitoring suhu dan kelembaban, sensor MQ4 untuk monitoring kadar gas metana dan Wemos D1 R1 sebagai pusat pengolahan data dan komunikasi antara sensor dan aplikasi blynk. Berdasarkan hasil pengujian didapatkan selisih antara pembacaan sensor dht22 dengan alat kalibrasi untuk suhu sebesar $1.2{ }^{\circ} \mathrm{C}$ dengan error $3.6 \%$ dan untuk kelembaban sebesar $0.1 \%$ dengan error sebesar $1 \%$. Sedangkan untuk kadar gas metana pada hari pertama sebesar 324 ppm dan berangsur turun sampai hari ke-10 yaitu sebesar 227 ppm. Dapat disimpulkan bahwa sistem monitoring bekerja dengan baik serta suhu dan kelembaban sesuai dengan standar, yaitu $35^{\circ} \mathrm{C}-45^{\circ} \mathrm{C}$ untuk suhu dan $40 \%-60 \%$ untuk kelembaban.

Kata kunci — Pupuk Kompos, Suhu, Kelembaban, Gas Metana, IoT.

Abstract - In the composting process, temperature and humidity must be stable, not too dry or too humid so that bacteria and microbes in the decomposition process do not die and can work optimally. In the composting process, the materials used are decomposing which produces methane gas. High levels of methane gas are dangerous if inhaled by humans and can cause damage to ozone causing the greenhouse effect. Therefore, a monitoring system was made in the composting tool with the Internet of Things (IoT) system so that users can easily monitor conditions of temperature, humidity, and methane gas content in the compost during the composting process. In this study, the DHT22 sensor was used for monitoring temperature and humidity, the MQ4 sensor for monitoring methane gas levels and Wemos D1 R1 as a data processing center and communication between the sensor and the Blynk application. Based on the test results, it was found that the difference between the dht 22 sensor reading with the calibration tool for temperature was $1.2^{\circ} \mathrm{C}$ with an error of $3.6 \%$ and for humidity was $0.1 \%$ with an error of $1 \%$. Meanwhile, the level of methane gas on the first day was $324 \mathrm{ppm}$ and gradually decreased until the 10th day, which was $227 \mathrm{ppm}$. It can be concluded that the monitoring system works well and the temperature and humidity are in accordance with the standards, namely $35^{\circ} \mathrm{C}-45^{\circ} \mathrm{C}$ for temperature and $40 \%-60 \%$ for humidity.

Keywords - Pupuk Kompos, Suhu, Kelembaban, Gas Metana, IoT. 


\section{PENDAHULUAN}

\section{A. Latar Belakang}

Pupuk kompos memiliki peranan penting dalam proses pertumbuhan tanaman, pupuk berperan sebagai penyuplai nutrisi tambahan agar kualitas tanaman menjadi lebih bagus dan tumbuh subur. Penggunaan pupuk ataupun bahan lain yang sifatnya organik dimaksudkan untuk mengurangi masalah yang sekarang timbul akibat dipakainya bahan-bahan kimia yang telah terbukti merusak tanah dan lingkungan [1]. Pengomposan sampah organik secara alami diuraikan oleh berbagai jenis mikroba atau jasad renik seperti bakteri, jamur, aktinomicetes, dsb. Proses peruraian ini memerlukan kondisi yang optimal seperti ketersediaan nutrisi yang memadai, udara yang cukup, kelembapan yang tepat, dsb.

Agar kualitas pupuk kompos yang dibuat memiliki kualitas yang baik, pada proses pembuatannya suhu dan kelembaban sangat berpengaruh pada pupuk kompos yang dibuat. Pada proses pembuatan bahan tidak boleh terlalu kering atau terlalu lembab, jika terlalu kering maka bakteri dan mikroba pada proses penguraian pupuk akan mati yang berdampak proses pembuatannya akan semakin lama [2].

Biasanya pembuatan pupuk kompos masih menggunakan cara manual dalam pengadukannya yang menguras banyak energi untuk mengaduk bahan tersebut dalam jumlah produksi skala besar. Pembuatan pupuk kompos ini memerlukan jangka waktu 2 sampai 4 minggu hingga kompos matang dengan sempurna.Pada proses pembuatan pupuk kompos, bahan-bahan yang membusuk terutama dari kotoran hewan mengeluarkan gas metana. Jika gas metana dengan jumlah tinggi terhisap oleh tubuh manusia, dapat mengakibatkan gangguan saluran pernafasan. Selain itu gas metana dalam jumlah yang banyak dapat merusak ozon dan menyebabkan efek rumah kaca.
Dari latar belakang di atas maka dibuatlah sebuah alat yang bernama Sistem Kompos Pintar berbasis IoT (SIKOMPI), yang bertujuan untuk mempermudah pengguna dalam membuat pupuk kompos organik, pada alat ini juga dilengkapi dengan teknologi Internet of Things (IoT) agar pengguna dapat dengan mudah memonitoring kondisi suhu, kelembaban, dan kandungan gas methana pada proses pembuatan pupuk kompos.

\section{TINJAUAN PUSTAKA}

\section{A. Internet of Things (IoT)}

Kevin ashton adalah orang yang pertama kali menemukan konsep Internet of Things (IoT) pada tahun 1999. Internet of Things adalah satu konsep yang sangat membantu manusia melakukan berbagai aktifitas seharihari, seperti sensor, manusia, LED dan benda-benda yang dapat di monitor dan di kendalikan dengan jarak jauh. Internet of Things berfungsi sebagai komunikasi yang dapat bertukar informasi melalui internet, mengumpulkan data, penyimpanan data yang kemudian data tersebut di simpan dalam cloud server (internet) [4].

\section{B. Pupuk}

Pupuk adalah material yang ditambahkan pada media tanam atau tanaman untuk mencukupi kebutuhan hara yang diperlukan tanaman sehingga mampu bereproduksi dengan baik. Material pupuk dapat berupa bahan organik ataupun non-organik (mineral) Pupuk berbeda dari suplemen, pupuk mengandung bahan baku yang diperlukan pertumbuhan dan perkembangan tanaman, sementara suplemen seperti hormon tumbuhan membantu kelancaran proses metabolisme. Dalam pemberian pupuk perlu diperhatikan kebutuhan tumbuhan tersebut, agar tumbuhan tidak mendapat terlalu banyak zat makanan. Terlalu sedikit atau terlalu banyak zat makanan dapat berbahaya bagi 
tumbuhan. Pupuk dapat diberikan lewat tanah ataupun disemprotkan ke daun. Salah satu jenis pupuk organik adalah kompos [3]. Bentuk pupuk kompos dapat dilihat pada gambar 1.

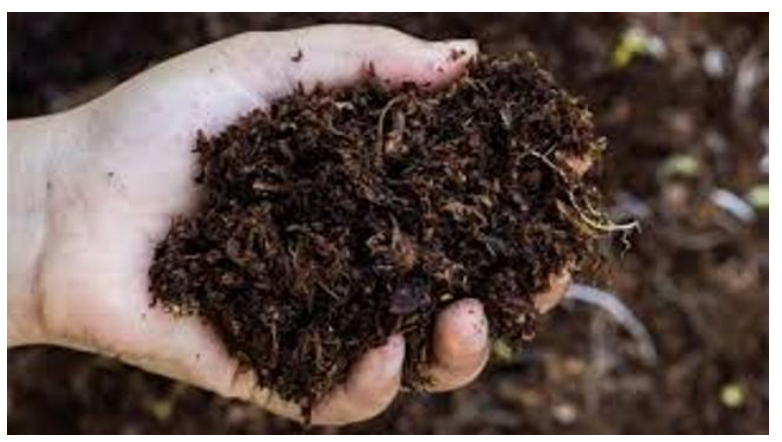

Gbr. 1 Pupuk Kompos

\section{Temperatur (Suhu)}

Suhu atau temperatur merupakan suatu besaran yang menunjukkan derajat panas suatu benda. Dimana semakin tinggi energi atom-atom penyusun benda tersebut maka semakin tinggi pula suhunya. Suhu dapat dinyatakan dalam 4 macam besaran yaitu ${ }^{\circ}$ Celcius, ${ }^{\circ}$ Kelvin, ${ }^{\circ}$ Farenheit dan ${ }^{\circ}$ Reamur. Menjaga kestabilan suhu pada suhu ideal 35 ${ }^{\circ} \mathrm{C}-45^{\circ} \mathrm{C}$ sangat penting dalam pembuatan kompos agar proses penguraian oleh mikroorganisme ataupun makroorganisme berjalan dengan optimal. Sedangkan untuk suhu akan terjadi peningkatan secara cepat dalam tumpukan kompos pada kisaran $30{ }^{\circ} \mathrm{C}$ hingga $60{ }^{\circ} \mathrm{C}$ [14].

\section{Kelembaban}

Kelembaban adalah tingkat kebasahan udara (jumlah air yang terkandung di udara) yang dinyatakan dengan persentase nisbi/relatif terhadap titik jenuhnya. Satuan kelembaban yang umum digunakan adalah RH, yaitu Relative Humidity atau kelembaban relatif. RH adalah satuan pengukuran yang merepresentasikan jumlah titik-titik air di udara pada suhu tertentu yang dibandingkan dengan jumlah maksimum titik-titik air yang dapat dikandung di udara pada suhu tersebut. RH dinyatakan dalam nilai persentase.

Kelembaban memegang peranan penting dalam metabolisme mikroba sehingga harus dijaga pada kisaran $40 \%$ hingga $60 \%$. Kelembaban yang tinggi (bahan dalam keadaan becek) akan mengakibatkan volume udara menjadi berkurang. Makin basah timbunan bahan maka kegiatan mengaduk harus makin sering dilakukan. Dengan demikian, volume udara terjaga stabilitasnya dan pembiakan bakteri anaerobik bisa dicegah. Sampah-sampah hijau umumnya tidak membutuhkan air sama sekali pada awal pembuatan kompos [14].

Ada tiga macam kelembaban udara antara lain:

1) Kelembaban nisbi (Relative Humidity)

Kelembaban nisbi merupakan perbandingan antara massa uap air yang terkandung dalam satu satuan volume udara dengan massa uap air maksimum yang dapat dikandung pada suhu dan tekanan yang sama. Sehingga dapat dikatakan bahwa kelembaban nisbi merupakan perbandingan antara tekanan uap air dengan tekanan uap air jenuh pada suhu yang sama. Dimana satuan dari Relative Humidity dinyatakan dalam bentuk \%.

\section{2) Kelembaban spesifik}

Kelembaban spesifik merupakan metode mengukur jumlah uap air di udara dengan rasio terhadap uap air di udara kering. Kelembaban spesifik dinyatakan dalam rasio kilogram uap air(mw), per kilogram udara, (ma).

3) Kelembaban mutlak:

Kelembaban mutlak merupakan massa uap air yang terkandung dalam satu satuan udara yang dinyatakan dalam satuan gram $/ \mathrm{m} 3$. Tentu saja bidang-bidang sains dan teknologi lainnya juga memakai meskipun dalam frekuensi yang lebih rendah [1]. Kelembaban memegang peranan penting dalam metabolisme mikroba sehingga harus dijaga pada kisaran $40 \%$ hingga $60 \%$. Kelembaban yang tinggi (bahan dalam keadaan becek) akan mengakibatkan volume udara menjadi berkurang. Makin basah timbunan bahan maka kegiatan mengaduk harus makin sering dilakukan. Dengan demikian, volume udara terjaga stabilitasnya dan pembiakan bakteri anaerobik bisa dicegah. Sampah-sampah hijau umumnya tidak membutuhkan air sama sekali pada awal pembuatan kompos. 


\section{E. Gas Metana}

Metana adalah hidrokarbon yang bentuknya menyerupai gas dan gas metana biasanya ditulis dengan rumus kimia $\mathrm{CH} 4$. Gas metana yang murni biasanya tak akan menimbulkan bau dan bila gas ini digunakan untuk keperluan komersil, maka biasanya ditambahkan bau belerang untuk mendeteksi suatu kebocoran yang bisa saja terjadi.

Gas metana adalah komponen utama dalam gas alam dan metana menjadi sumber bahan bakar utama. Pada saat satu molekul gas metana dibakar dengan oksigen, maka akan menghasilkan karbondioksida dan dan 2 molekul air. Gas metana juga menjadi salah satu gas rumah kaca yang sangat kuat untuk mencegah terjadinya pemanasan global dan pembuatan gas metana terjadi secara alami.

Gas metana menjadi alternatif sumber energi yang banyak digunakan belakangan ini dan dengan perkembangan jaman, kini manusia bisa menghasilkan gas metana dengan proses rekayasa yang dilakukan pada pertumbuhan bakteri yang bisa menghasilkan sebuah gas salah satunya yaitu dalam pembuatan pupuk kompos. Berbagai penyakit yang bisa menyerang tanaman dapat dicegah dengan gas metana yang terdapat pada pupuk kompos.

\section{F. Sensor DHT 22}

Sensor dht 22 pada penelitian ini berfungsi untuk memonitoring suhu dan kelembaban didalam tong pengaduk pada saat pembuatan pupuk kompos. Dengan adanya sensor ini pengguna dapat mengetahui kelembaban dan suhu saat pembuatan serta dapat memberikan informasi jika kelembabannya kurang atau berlebih, suhunya kurang atau berlebih. Sensor dht 22 dipilih karena memiliki range pengukuran yang luas yaitu 0 sampai $100 \%$ untuk kelembaban dan -40 derajat celcius sampai 125 derajat celcius untuk suhu. Sensor ini juga memiliki output digital (single-bus) dengan akurasi yang tinggi dan presisi dalam hal pengukuran. Bentuk sensor dht 22 dapat dilihat pada gambar 2 .

\begin{tabular}{|cc|}
\hline & DHT22 pins \\
\hline 1 & VCC \\
2 & DATA \\
3 & NC \\
4 & GND \\
\hline
\end{tabular}

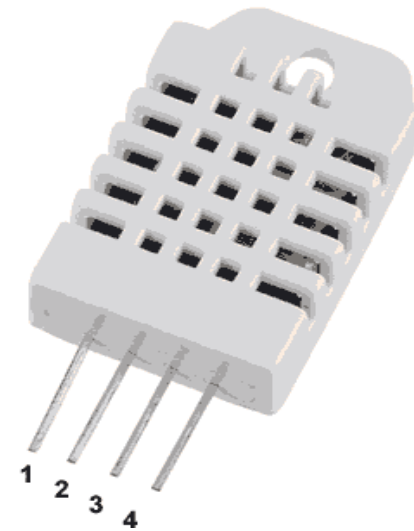

Gbr. 2 Sensor DHT22

\section{G. Sensor MQ4}

Sensor mq 4 merupakan modul sensor yang mampu mendeteksi kadar gas metana serta gas natural yang terdapat di udara. Sensitivitas sensor mq4 ini sangat tinggi terhadap gas metana. Mq4 memiliki kemampuan mendeteksi konsentrasi gas metana $(\mathrm{CH})$ di udara. Sensor dapat digunakan untuk mendeteksi gas yang mudah terbakar. Sensor ini membutuhkan suplai daya sebesar 5V. Jangkauan deteksinya terhadap natural gas/metana adalah 300 sampai 10000 ppm. Sensor mq4 pada alat ini berfungsi untuk memonitoring berapa banyak kadar gas metana yang dihasilkan pada saat pembuatan pupuk kompos. Bentuk sensor mq4 dapat dilihat pada gambar 3.

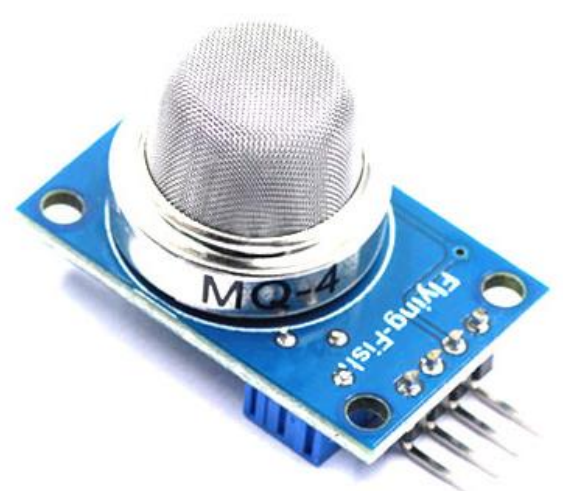

Gbr. 3 Sensor MQ4

\section{H. Modul wifi Esp8266}

ESP8266 adalah sebuah komponen chip terintegrasi yang didesain untuk keperluan dunia masa kini yang serba tersambung. Chip ini menawarkan solusi networking Wi-Fi yang lengkap dan menyatu, yang dapat digunakan sebagai penyedia aplikasi atau untuk memisahkan semua fungsi networking Wi-Fi ke pemproses aplikasi lainnya. 
ESP8266 memiliki kemampuan on-board prosesing dan storage yang memungkinkan chip tersebut untuk diintegrasikan dengan sensor-sensor atau dengan aplikasi alat tertentu melalui pin input output hanya dengan pemrograman singkat. Bentuk modul wifi dapat dilihat pada gambar 4 .

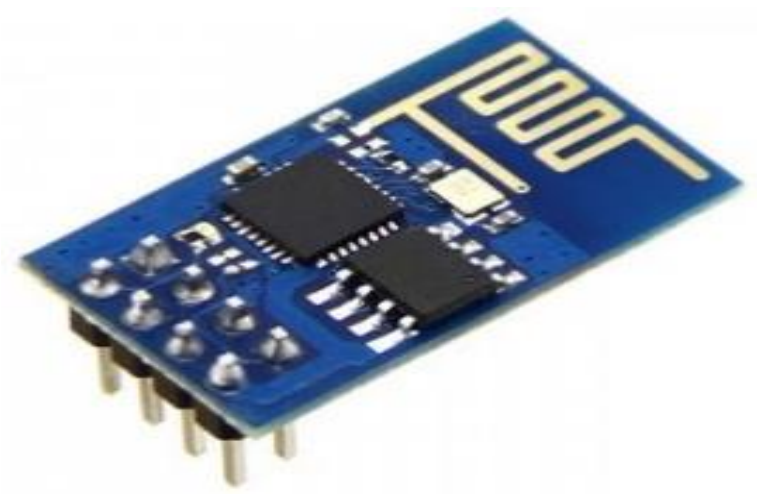

Gbr. 4 Modul Wifi Esp8266

\section{Wemos D1 Rl}

Wemos merupakan salah satu mikrokontroler yang mempunyai fungsi dan kegunaan layaknya arduino tetapi mempunyai beberapa keunggulan dari beberapa mikrokontroler lainnya, sehingga sering digunakan untuk konsep IoT (Saputro, 2017). Wemos d1 r1 adalah wifi development board berbasis esp8266 MOD alias esp-12 dengan bentuk persis dengan arduino uno r3. Board ini kompatibel dan bisa diprogram dengan dengan arduino IDE. Board d1 r1 ini memiiki colokan power supply sehingga bisa dinyalakan dengan adaptor hingga $12 \mathrm{~V}$. Board ini kompatibel dengan firmware Tasmota yang memudahkan project IoT Anda. Bentuk wemos d1 r1 dapat dilihat pada gambar 5 .

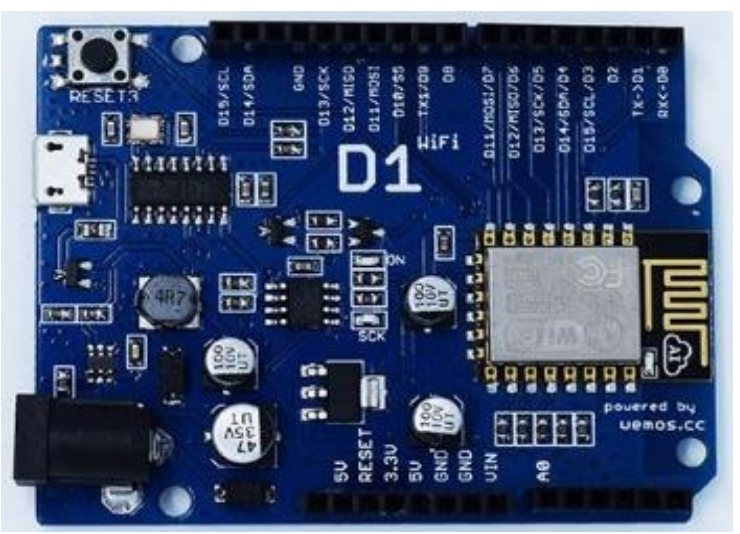

Gbr. 5 Wemos R1 D1

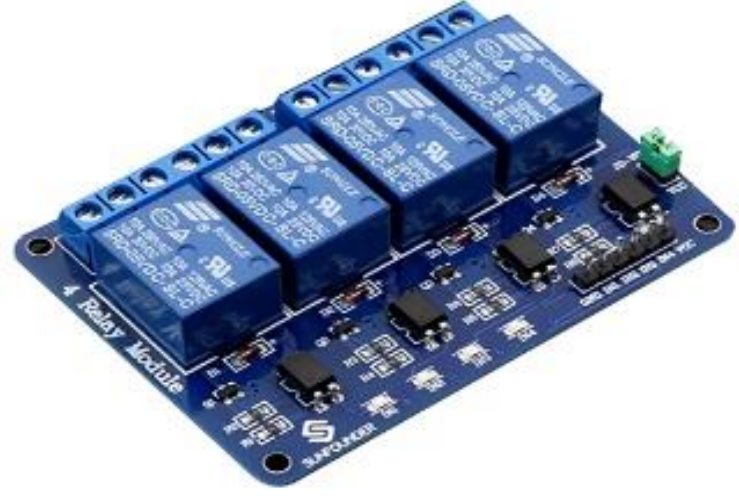

Gbr. 6 Modul Relay 4 Chanel 5V

\section{J. Modul Relay}

Modul relay adalah saklar yang dioperasikan secara elektrik yang memungkinkan untuk menghidupkan atau mematikan sirkuit dengan menggunakan voltase atau arus yang jauh lebih tinggi daripada yang dapat ditangani oleh NodeMCU. Relay melindungi setiap rangkaian dari satu sama lain. Setiap saluran dalam modul ini memiliki tiga koneksi bernama NC, COM, dan NO. Bagian NC dan NO relay digunakan untuk menghubungkan sumber listrik (kabel fasa) dengan terminal SPO. Jenis kontak yang digunakan di perangkat ini ialah Normally Closed (NC) sehingga pada kondisi arus normal sambungan sumber ke SPO tertutup. Sedangkan pada saat arus lebih, kontak akan otomatis diputuskan (open).Bagian belitan (coil) relay disambungkan ke pin pengendali NodeMCU melalui switch transistor. Rangkaian relay yang dipilih ialah modul relay 4 channel $5 \mathrm{~V}$ seperti diperlihatkan pada gambar 6. dibawah ini:

\section{METODOLOGI PENELITIAN}

\section{A. Instrumen Penelitian}

1) Perangkat Keras (Hardware)

Alat yang digunakan dalam penelitian yaitu Arduino wemos d1 r1 yg sudah terintegrasi dengan modul wifi esp8266 sebagai pusat pemprosesan dan kendali kontrol pada alat. Sehingga data-data dari sensor dht 22, pH, dan mq 4 dapat langsung di monitoring pada aplikasi blynk, dengan adanya akses wifi yang dimiliki oleh modul esp8266 tersebut dan mengirimkan notifikasi 
di aplikasi blynk. Alat dan bahan yang digunakan dapat dilihat pada tabel 1 . dibawah ini:

Tabel 1. Alat dan Bahan

\begin{tabular}{|l|l|}
\hline No. & Perangkat keras yang digunakan \\
\hline 1. & Laptop \\
\hline 2. & Smartphone Android \\
\hline 3. & Wemos D1 R1 \\
\hline 4. & Sensor MQ-4 \\
\hline 5. & Sensor DHT22 \\
\hline 6. & Relay \\
\hline 7. & Pompa air DC 1 buah \\
\hline 8. & Kabel Jumper \\
\hline 9. & Baterai 9V \\
\hline
\end{tabular}

\section{2) Perangkat Lunak (Software)}

Pada penelitian ini digunakan software Blynk yang digunakan untuk memonitoring suhu dan kelembaban, gas metana, ph dan kontrol motor melalui aplikasi yang dibuat menggunakan smartphone. Berikut tampilan aplikasi monitoringnya:

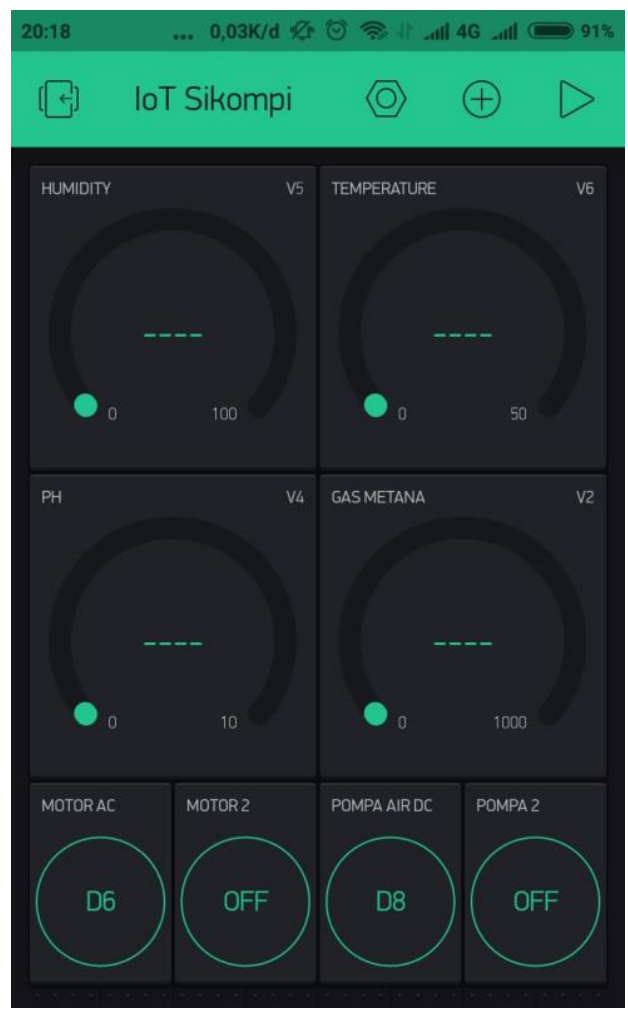

Gbr. 7 Desain Aplikasi monitoring dengan Blynk
Pertama digunakan Arduino ide untuk membuat program yang dapat terintegrasi dengan aplikasi blynk yang nantinya digunakan untuk monitoring, setelah pembuatan program pada software arduino berhasil, selanjutnya program akan di upload kedalam mikrokontroller yang ada pada board wemos d1 r1, lalu selanjutnya akan diintegrasikan dengan aplikasi blynk yang sudah didesain sedemikian rupa seperti tampilan diatas untuk monitoring dan kontrol.

\section{B. Tahapan Penelitian}

Metode Penelitian yang digunakan dalam penelitian ini yaitu melakukan studi literatur yang mendukung penelitian seperti konsep dari IoT itu sendiri. Selain itu juga dilakukan untuk melihat bagaimana suhu, kelembaban, tingkat $\mathrm{pH}$, dan kandungan gas metana pada kompos itu sendiri. Metode tersebut ditampilkan dalam bentuk diagram alir penelitian pada gambar 8 terdiri dari studi literatur dan bimbingan, identifikasi kebutuhan sistem, perancangan sistem monitoring dan pengujian sistem.

Penjelasan alur Flowchart :

- Langkah pertama yaitu analisa kebutuhan, pada bagian ini dilakukan studi literatur dan menyiapkan komponen-komponen apa saja yang akan digunakan dan spesifikasi yang tepat untuk monitoringnya.

- Setelah semua komponen hardware sudah siap, dilakukan perancangan pada bagian hardware. Diantaranya pemasangan sensor-sensor, pengabelan dan penyiapan box kontrol.

- Setelah bagian hardware selesai, kemudian dilakukan pembuatan koding dan mendesain tampilan aplikasi untuk monitoringnya.

- Setelah semua sudah dirancang dan terkoneksi satu sama lain, dilakukan pengujian alat, dimana semua sensor diuji dan dikalibrasi, apakah berjalan dengan baik atau tidak.

- Jika semua sensor berfungsi dengan baik, tahap selanjutnya yaitu dilakukan pengambilan data dan dilakukan analisis data. 


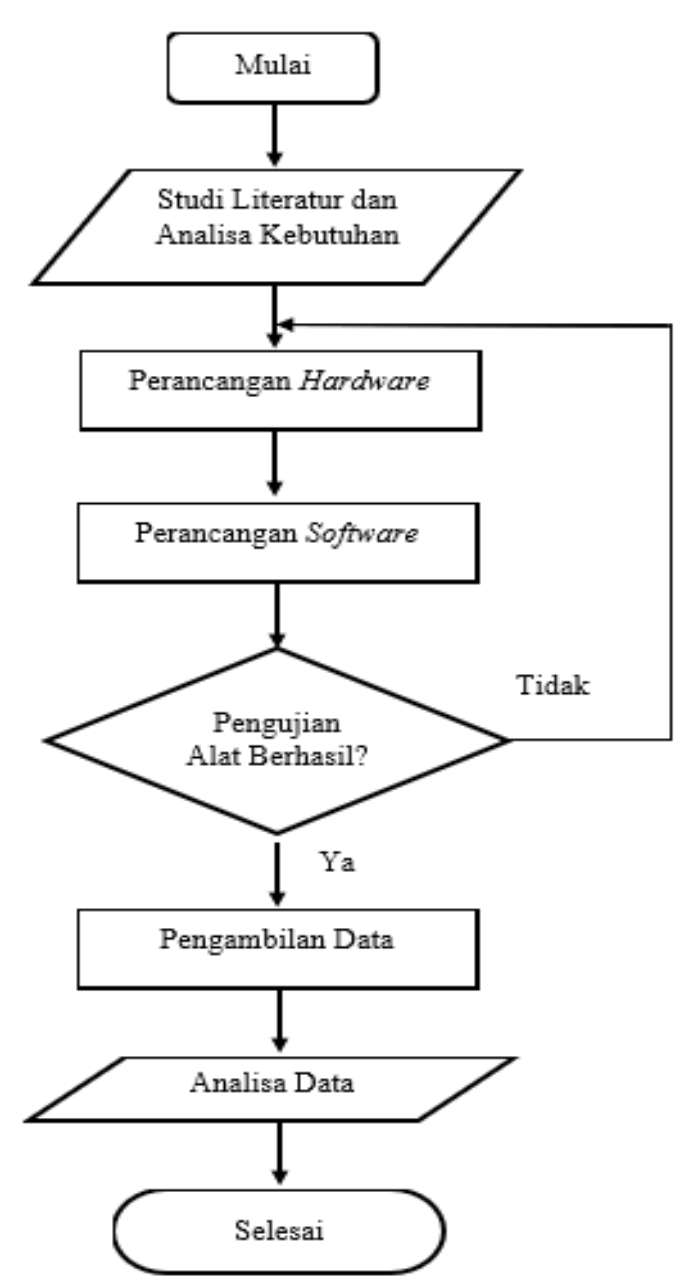

Gbr. 8 Flowchart Tahapan Penelitian

C. Perancangan Sistem

1) Rancangan Sistem Keseluruhan
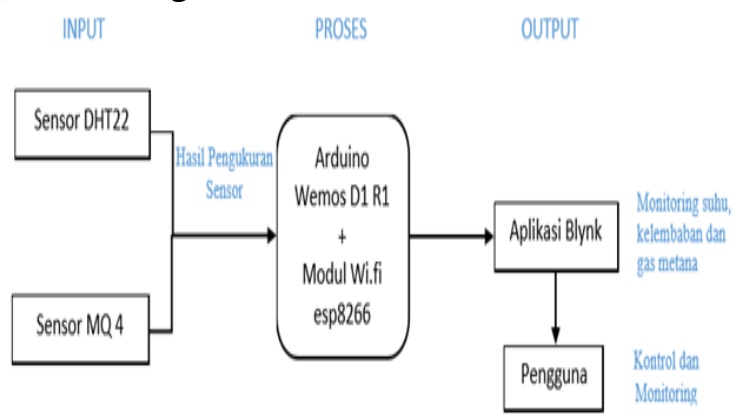

Gbr. 9 Diagram Rancangan Sistem Keseluruhan

Gambar 9 memperlihatkan arsitektur sistem yang diterapkan penulis dalam penelitian. Perangkat sistem monitoring dan otomatisasi kendali motor ac dan dc terhubung ke mikrokontroler wemos d1 r1 sebagai proses terpusat untuk menerima I/O. Pada perangkat monitoring aplikasi blynk menampilkan hasil informasi data suhu, kelembapan, $\mathrm{pH}$, dan kandungan gas metana. Proses pengadukan dan pemberian air atau larutan EM4 dikendalikan menggunakan smarthphone.

2) Skematik Rangkaian

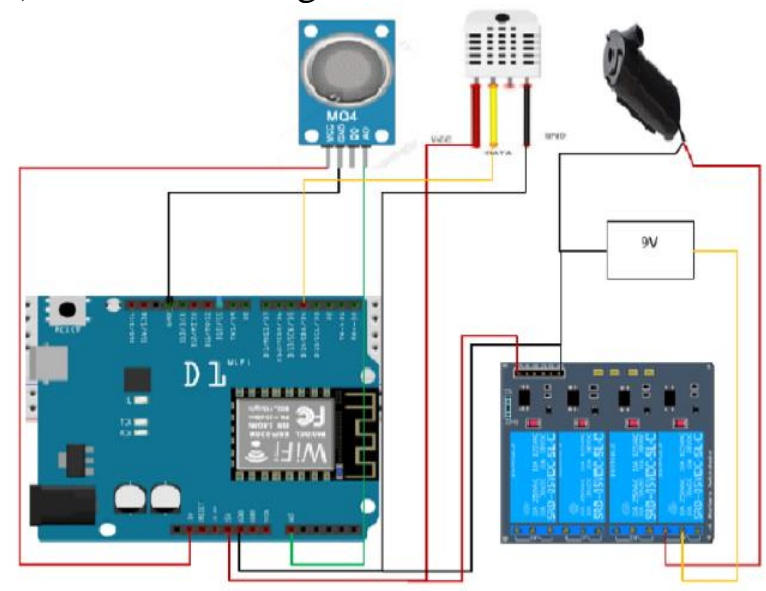

Gbr. 10 Skematik Rangkaian Sensor MQ-4 dan DHT22

Dari gambar 10 diatas ada 2 jenis sensor yang digunakan, yang pertama adalah sensor dht 22 yang berfungsi untuk mendeteksi suhu dan kelembaban dah sensor mq 4 berfungsi untuk mendeteksi kandungan gas metana pada kompos. Data yang didapat dari kedua sensor ini akan diproses di mikrokontroller wemos d1 r1 untuk dikirimkan ke layar monitor aplikasi blynk dengan menggunakan modul wifi esp8266 yang sudah terintegrasi dengan wemos d1 r1. Pada bagian kanan terdapat rangkaian relay, baterai $9 \mathrm{v}$, dan pompa air dc yang berfungsi untuk menyemprotkan air, pompa air akan hidup secara otomatis jika kelembaban dibawah ketentuan yang sudah disetting sebelumnya.

3) Desain Perangkat Keras

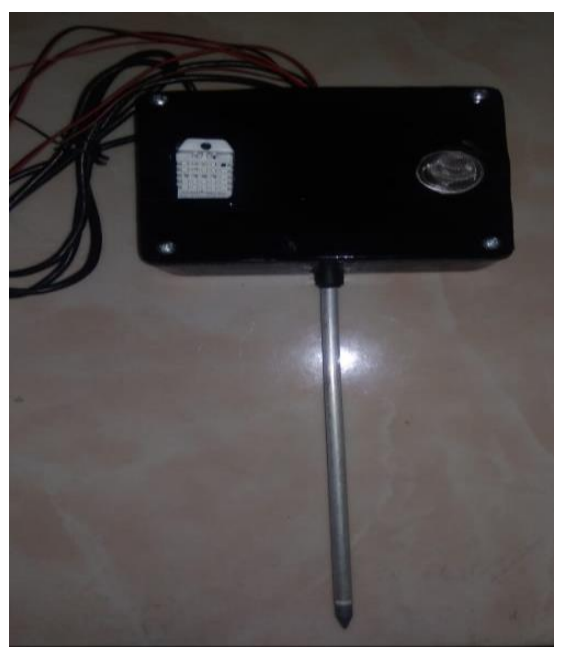

Gbr. 11 Desain perangkat keras tampak depan 
Gambar 11 diatas merupakan hasil akhir atau cover depan rangkaian, pada sebelah kiri yang berwarna putih merupakan sensor DHT22, pada bagian tengah merupakan sensor $\mathrm{pH}$, dan pada bagian kanan merupakan sensor MQ-4 yang sudah di susun sedemikian rupa dan diberi cover.

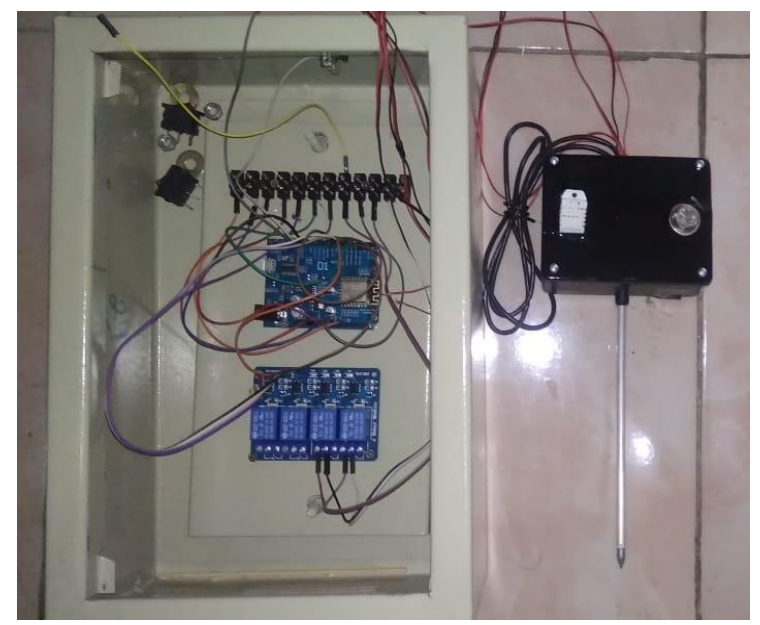

Gbr. 12 Desain perangkat keras tampak keseluruhan

Pada gambar 12 merupakan hasil keseluruhan rangkaian untuk monitoring, rangkaian sudah disusun dalam box panel dan sensor sudah tertata rapih. Bagian sensor-sensor pun sudah terhubung dengan komponen lainnya.

\section{HASIL DAN PEMBAHASAN}

Setelah semua rangkaian sudah terpasang dengan baik, dilakukan pengujian secara keseluruhan pada rangkaian baik software maupun hardware. Pengujian ini dilakukan untuk mengetahui apakah sensor-sensor, komponen, dan software berjalan dengan baik atau tidak. Berikut adalah hasil pengujiannya:

\section{A. Hasil Pengujian Hardware}

\section{1) Sensor DHT22}

Proses pengambilan data dilakukan setiap 1 hari sekali selama 10 hari dan pada jam yang sama. Untuk kalibrasi atau perbandingan data, digunakan alat pengukur suhu dan kelembaban digital. Data hasil pengukuran sensor dht22 dapat dilihat pada tabel 2 dibawah ini.
Table 2. Data Hasil Pengujian Sensor DHT22

\begin{tabular}{|c|c|c|c|c|}
\hline Ket. & Parameter & $\begin{array}{l}\text { Sensor } \\
\text { DHT22 } \\
\end{array}$ & $\begin{array}{c}\text { Alat } \\
\text { Kalibrasi }\end{array}$ & Error \\
\hline \multirow{2}{*}{$\begin{array}{l}\text { Data } \\
\text { ke-1 }\end{array}$} & $\mathrm{T}$ & $28^{\circ} \mathrm{C}$ & $29.6^{\circ} \mathrm{C}$ & $5.4 \%$ \\
\hline & $\mathrm{H}$ & $96 \%$ & $99 \%$ & $3.0 \%$ \\
\hline \multirow{2}{*}{$\begin{array}{l}\text { Data } \\
\text { ke-2 }\end{array}$} & $\mathrm{T}$ & $35^{\circ} \mathrm{C}$ & $36.2^{\circ} \mathrm{C}$ & $3.3 \%$ \\
\hline & $\mathrm{H}$ & $99 \%$ & $99 \%$ & $0 \%$ \\
\hline \multirow{2}{*}{$\begin{array}{l}\text { Data } \\
\text { ke-3 }\end{array}$} & $\mathrm{T}$ & $34{ }^{\circ} \mathrm{C}$ & $35.9^{\circ} \mathrm{C}$ & $5.2 \%$ \\
\hline & $\mathrm{H}$ & $99 \%$ & $99 \%$ & $0 \%$ \\
\hline \multirow{2}{*}{$\begin{array}{l}\text { Data } \\
\text { ke-4 }\end{array}$} & $\mathrm{T}$ & $31^{\circ} \mathrm{C}$ & $32.9^{\circ} \mathrm{C}$ & $5.7 \%$ \\
\hline & $\mathrm{H}$ & $90 \%$ & $88 \%$ & $2.2 \%$ \\
\hline \multirow{2}{*}{$\begin{array}{l}\text { Data } \\
\text { ke-5 }\end{array}$} & $\mathrm{T}$ & $31^{\circ} \mathrm{C}$ & $31.9^{\circ} \mathrm{C}$ & $2.8 \%$ \\
\hline & $\mathrm{H}$ & $85 \%$ & $84 \%$ & $1.2 \%$ \\
\hline \multirow{2}{*}{$\begin{array}{l}\text { Data } \\
7 \mathrm{ke}-6\end{array}$} & $\mathrm{~T}$ & $31{ }^{\circ} \mathrm{C}$ & $32.1^{\circ} \mathrm{C}$ & $3.4 \%$ \\
\hline & $\mathrm{H}$ & $82 \%$ & $82 \%$ & $0 \%$ \\
\hline \multirow{2}{*}{$\begin{array}{l}\text { Data } \\
\text { ke-7 }\end{array}$} & $\mathrm{T}$ & $31{ }^{\circ} \mathrm{C}$ & $31.9^{\circ} \mathrm{C}$ & $2.8 \%$ \\
\hline & $\mathrm{H}$ & $80 \%$ & $80 \%$ & $0 \%$ \\
\hline \multirow{2}{*}{$\begin{array}{l}\text { Data } \\
\text { ke-8 }\end{array}$} & $\mathrm{T}$ & $32{ }^{\circ} \mathrm{C}$ & $32.5^{\circ} \mathrm{C}$ & $1.5 \%$ \\
\hline & $\mathrm{H}$ & $82 \%$ & $83 \%$ & $1.2 \%$ \\
\hline \multirow{2}{*}{$\begin{array}{l}\text { Data } \\
\text { ke-9 }\end{array}$} & $\mathrm{T}$ & $31^{\circ} \mathrm{C}$ & $32^{\circ} \mathrm{C}$ & $3.1 \%$ \\
\hline & $\mathrm{H}$ & $82 \%$ & $81 \%$ & $1.2 \%$ \\
\hline \multirow{2}{*}{$\begin{array}{l}\text { Data } \\
\text { ke-10 }\end{array}$} & $\mathrm{T}$ & $30^{\circ} \mathrm{C}$ & $31^{\circ} \mathrm{C}$ & $3.2 \%$ \\
\hline & $\mathrm{H}$ & $81 \%$ & $80 \%$ & $1.2 \%$ \\
\hline \multirow{2}{*}{$\begin{array}{l}\text { Rata- } \\
\text { rata }\end{array}$} & $\mathrm{T}$ & $31.4^{\circ} \mathrm{C}$ & $32.6^{\circ} \mathrm{C}$ & $3.6 \%$ \\
\hline & $\mathrm{H}$ & $87.6 \%$ & $87.5 \%$ & $1 \%$ \\
\hline
\end{tabular}

Keterangan : $\quad \mathrm{T}:$ Temperature $\mathrm{H}$ : Humidity

Untuk nilai suhunya relatif stabil di angka 30 - $36{ }^{\circ} \mathrm{C}$, keadaan tersebut sudah termasuk ideal. Pada saat pertama kali dibuat suhu dan kelembaban akan meningkat, namun perlahan akan turun dan stabil di suhu kamar yaitu $20-25{ }^{\circ} \mathrm{C}$. Pada penelitian yang dilakukan nilai suhunya relative di angka 30 - $36{ }^{\circ} \mathrm{C}$ karena pengambilan data hanya sampai 10 hari dimana suhu masih terbilang tinggi. Penyebab tingginya suhu juga bisa terjadi karena pada penelitian ini menggunakan system anaerob pada proses pengomposannya, sehingga suhu meningkat dan kelembaban juga meningkat dikarenakan tidak ada sirkulasi udara yang keluar atau masuk. Error pada bagian pembacaan nilai suhu yaitu 3.6\% dari alat kalibrasi, sehingga pada percobaan ini sensor DHT22 dinyatakan bekerja dengan baik.

Pada data hasil pengukuran kelembaban didapatkan nilai yang cukup tinggi yaitu berkisar diantara $80-99 \%$, hal tersebut sepertinya disebabkan oleh kondisi tong pengaduk yang bersifat anaerob. Kondisi tersebut terjadi karena pada saat pertama kali pupuk dibuat, suhu akan dalam keadaan tinggi, sehingga menyebabkan udara menjadi 
lembab dan dapat menyebabkan pengembunan pada sensor. Setelah beberapa hari, terjadi penurunan kelembaban secara perlahan. Error pada bagian pembacaan nilai kelembaban yaitu $1.0 \%$.

Berdasarkan penelitian yang telah dilakukan, untuk sistem monitoring suhu dan kelembaban berjalan dengan baik dan masih dalam batas toleransi. Batas toleransi error yaitu dibawah $5 \%$.

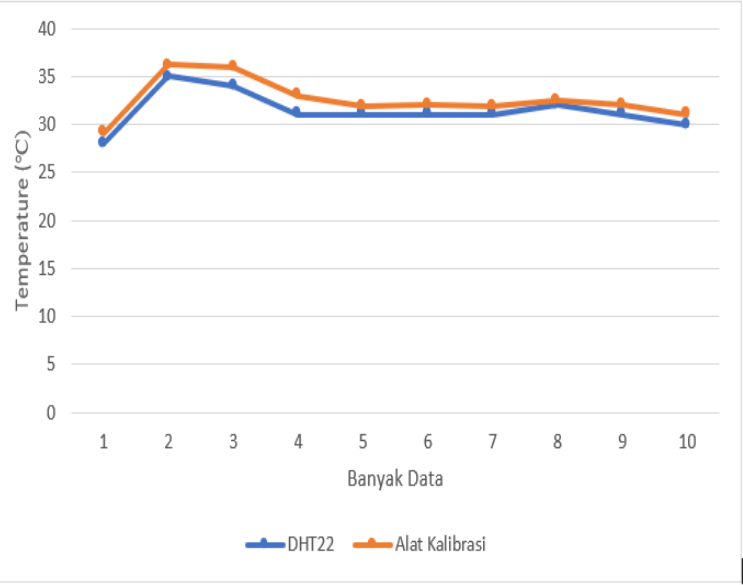

Gbr. 13 Linearitas data suhu Sensor DHT22

Dapat dilihat pada gambar 13, garis biru merupakan data hasil pengukuran sensor dht22 dan garis oranye merupakan data hasil pengukuran alat kalibrasi. Data diambil sebanyak 10 kali dan digambarkan pada titiktitiknya. Linearitas data pengukuran suhu antara dht22 dan alat kalibrasi cukup baik, hanya beberapa data yang sedikit berbeda. Data yang dihasilkan cukup presisi dengan alat kalibrasi, dengan ini sensor dht22 dinyatakan bekerja dengan baik.

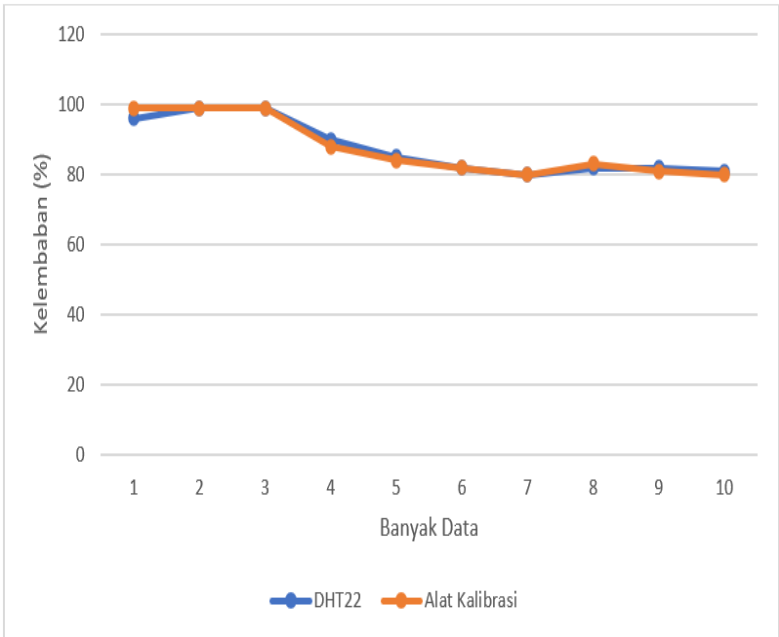

Gbr. 14 Linearitas data kelembaban Sensor DHT22
Dapat dilihat pada gambar 14, garis biru merupakan data hasil pengukuran sensor dht22 dan garis oranye merupakan data hasil pengukuran alat kalibrasi. Hasil pengukuran sensor dht22 sangat baik, bahkan hampir semua data pengukuran sama dengan data alat kalibrasi. Tingkat error pembacaannya hanya $1 \%$ dan rata-rata selisih datanya yaitu $0.1 \%$. Nilai kelembabannya menurun setiap harinya, dari saat pertama $99 \%$ hingga $80 \%$.

Dapat dilihat pada gambar 15 diatas merupakan tampilan aplikasi monitoring menggunakan blynk. Semua sensor bekerja dengan baik dan dapat ditampilkan diaplikasi blynk dengan baik. Pada aplikasi blynk terdapat beberapa parameter yang ditampilkan, yaitu Humidity atau kelembaban, temperature atau suhu, $\mathrm{pH}$, dan gas metana.

Dapat dilihat pada gambar 16 diatas merupakan tampilan alat kalibrasi yang digunakan saat pengambilan data.

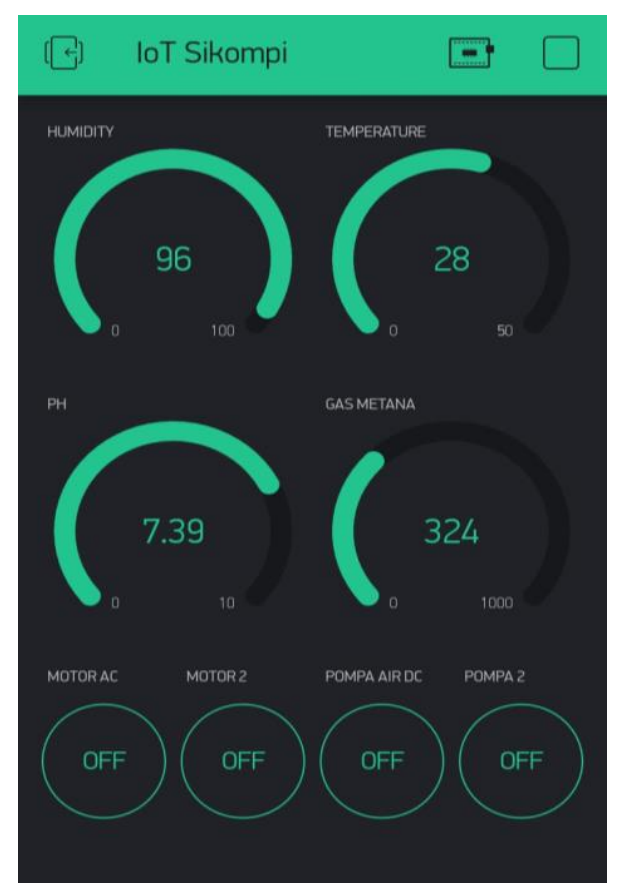

Gbr. 15 Tampilan pada blynk

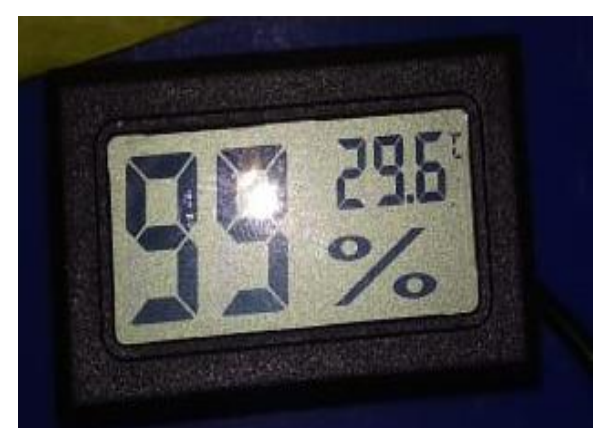

Gbr. 16 Tampilan alat kalibrasi saat pengukuran 


\section{2) Sensor MQ-4}

Proses pengambilan data dilakukan setiap 2 hari sekali selama 2 minggu dan pada jam yang sama. Pengujian ini bertujuan untuk memonitoring perubahan kadar gas metana pada proses pembuatan pupuk kompos sedang berlangsung, mulai dari kondisi awal saat pertama pupuk kompos baru di buat hingga pupuk kompos matang atau siap digunakan. Data hasil pengukuran sensor MQ4 dapat dilihat pada tabel 3 dibawah ini.

Berdasarkan data diatas, dapat dilihat pada hari pertama tingkat gas metananya yang paling tinggi diantara data lainnya. Tingginya kadar gas metana disebabkan oleh pembusukan bahan-bahan yang digunakan. Selain itu penggunakan kotoran hewan sebagai starter juga mengeluarkan gas metana yang cukup banyak.

Table 3. Data Hasil Pengujian Sensor MQ4

\begin{tabular}{|c|c|c|}
\hline No. & Keterangan & $\begin{array}{c}\text { Kandungan Gas } \\
\text { Metana }\end{array}$ \\
\hline 1. & $22-07-20 \quad 10: 00$ & $324 \mathrm{ppm}$ \\
\hline 2. & $23-07-20 \quad 10: 00$ & $295 \mathrm{ppm}$ \\
\hline 3. & $24-07-20 \quad 10: 00$ & $272 \mathrm{ppm}$ \\
\hline 4. & $25-07-20 \quad 10: 00$ & $254 \mathrm{ppm}$ \\
\hline 5. & $26-07-20 \quad 10: 00$ & $243 \mathrm{ppm}$ \\
\hline 6. & $27-07-20 \quad 10: 00$ & $260 \mathrm{ppm}$ \\
\hline 7. & $28-07-20 \quad 10: 00$ & $238 \mathrm{ppm}$ \\
\hline 8. & $29-07-20 \quad 10: 00$ & $230 \mathrm{ppm}$ \\
\hline 9. & $30-07-20 \quad 10: 00$ & $246 \mathrm{ppm}$ \\
\hline 10. & $31-07-20 \quad 10: 00$ & $227 \mathrm{ppm}$ \\
\hline \multicolumn{2}{|r|}{ Rata-rata } & $258.9 \mathrm{ppm}$ \\
\hline
\end{tabular}

Pada saat pengambilan data, kadar gas metana yang terbaca pada hari pertama yaitu 324 ppm, kemudian dilakukan pemberian sekam padi dan air dihari kedua menurun menjadi 295 ppm, dan dihari ketiga menjadi 272 ppm, dan seterusnya.

Berdasarkan penelitian yang dilakukan, pemberian sekam padi dan pemberian air dapat mengurangi kadar gas metana. Setelah pemberian sekam padi dan air, ternyata di hari ke 6 dan ke 9 terdapat kenaikan kadar gas metana sedikit, hal tersebut terjadi dikarenakan air yang tertampung di tong pengaduk lupa dikeluarkan.

Pada penelitian yang dilakukan, kadar gas metana tidak sampai melebihi angka 400 ppm, hal tersebut menandakan jika gas metana tersebut terhirup oleh manusia masih dalam batas aman. Jika kadar gas metana mencapai 1500 ppm atau lebih sudah termasuk dalam kategori bahaya untuk Kesehatan.

Untuk pembacaan data, sensor mq4 ini bekerja dengan baik. Sensitivitas sensor terhadap gas metana juga sangat baik, pada saat ada perubahan, dengan cepat sensor mq4 mendeteksinya dan mengirimkan datanya. Dapat dilihat pada gambar 17, grafik tersebut merupakan grafik pengukuran sensor mq4 yang digunakan pad apenelitian. Pengambilan data diambil sebanyak 10 kali dan pada jam yang sama. Dapat dilihat pada grafik, pada hari pertama kadar gas metananya berada pada range 300 ppm lebih, kemudian dihari kedua menurun setelah diberi sekam padi dan air. Dari grafik diatas semakin lama kadar gas metana semakin turun, itu menandakan bahwa proses pengomposan berjalan dengan baik, dimana hasil akhir output pupuk komposnya tidak berbau melainkan bau tanah.

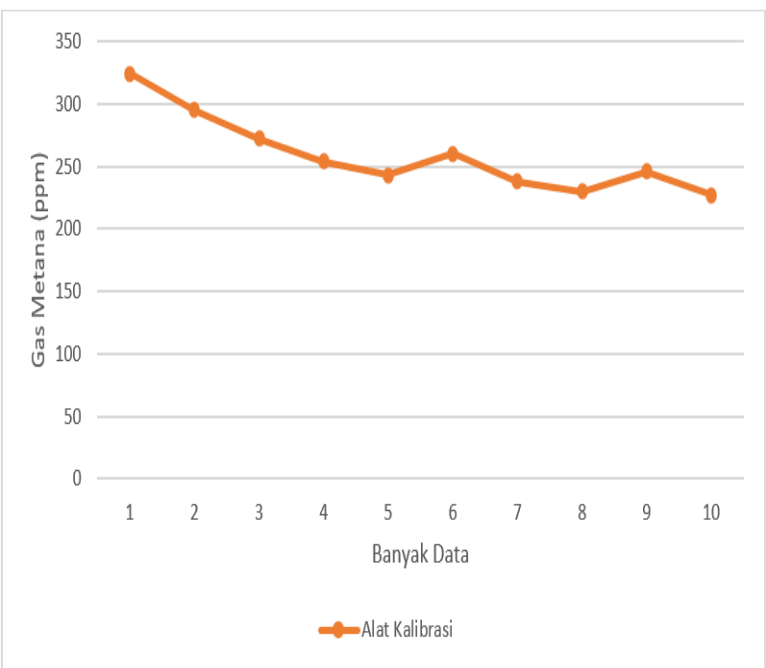

Gbr. 17 Grafik kadar gas metana.

\section{KESIMPULAN DAN SARAN}

\section{A. Kesimpulan}

Berdasarkan hasil penelitian yang telah dilakukan, dapat diambil kesimpulan bahwa:

1) Dari penelitian yang telah dilakukan, didapatkan hasil pengukuran kadar gas metana setiap harinya berbeda-beda yaitu dari 227 ppm sampai 324 ppm dengan rata-rata sebesar $258.9 \mathrm{ppm}$. Gas metana yang dihasilkan termasuk sedikit karena 
pada saat pengomposan, volume maksimal yang dapat ditampung tong hanya sebesar 23.3 liter.

2) Sistem monitoring yang dirancang berjalan dengan baik, error yang didapat masih dibawah standar batas maksimal error pembacaan yaitu 5\%. Didapatkan error untuk pengukuran suhu sebesar $3.6 \%$ dan error untuk pengukuran kelembaban sebesar $1 \%$.

\section{B. Saran}

Adapun saran untuk penelitian monitoring suhu, kelembaban dan gas metana ini untuk kedepannya yaitu:

1) Perbaikan desain box sensor agar posisi sensor menghadap samping dan tidak menghadap langsung kebawah agar tidak terjadi pengembunan pada sensor.

2) Menambahkan soket sambungan, agar pada saat proses bongkar pasang jika akan dilakukan pembersihan atau penggantian komponen sensor semakin lebih efisien dan jauh lebih mudah.

3) Dilakukan pengembangan lebih lanjut dengan menambahkan komponen lcd untuk memonitoring offline yang dipasang di box panel.

\section{UCAPAN TERIMA KASIH}

Saya ucapkan Terimakasih untuk keluarga saya yang selalu memberi semangat.

\section{REFERENSI}

[1] Riyo. 2016. "Rancang Bangun Sistem Monitoring Ph, Temperatur Dan Kelembaban Untuk Optimalisasi Pembuatan Pupuk Kompos Pada Fertilizer Maker". Institut Teknologi Sepuluh Nopember.

[2] Vandra, dkk "Monitoring Suhu dan Kelembaban Menggunakan Mikrokontroler ATMega328 pada Proses Dekomposisi Pupuk Kompos", Banda Aceh, Indonesia, 2017.

[3] Rio. 2010, Rancang Bangun Mesin Pembuat Pupuk Kompos Otomatis Berbasis Mikrokontroler. STIKOM Surabaya.

[4] Afrizal, M.A. 2018. Rancang Bangun Rumah Pintar Berbasis IOT (Internet of Things) Sebagai Media Pembelajaran pada Mata Pelajaran pemrograman, Mikroprosesor dan Mikrokontroller di SMKN2 Surabaya. Jurnal
Pendidikan Teknik Elektro. Vol.7, No.1, pp.79-86.

[5] Rahmawati, Novi,. Dony, Novria. 2014. "Pembuatan Pupuk Organik Berbahan Sampah Organik Rumah Tangga Dengan Penambahan Aktivator Em4 Di Daerah Kayu Tangi”. Fakultas Keguruan dan Ilmu Pendidikan Universitas Islam Kalimantan MAB Banjarmasin.

[6] Kusmiati, Florentina dkk. 2003. Pengaruh Kompos Dari Sampah Pasar Sebagai Substitusi Pupuk Anorganik Pada Tanaman Pakan. Fakutas peternakan universitas Diponegoro.

[7] Sriharti, Takiyah Salim. 2010. "Pemanfaatan Sampah Taman (Rumput-Rumputan) Untuk Pembuatan Kompos". Balai Besar Pengem bangan Teknologi Tepat Guna LIPI.

[8] Melati, H. P. 2014. "Teknologi Pembuatan Pupuk Organik". Universitas Malikussaleh.

[9] Ayuni, Sri,.Sari, Lina. 2019. "Sistem Monitoring dan Notifikasi Suhu dan Kelembaban Udara Pada Jamur Tiram Menggunakan ESP8266 Dengan Platform IOT”. Fakultas Teknik Universitas Riau.

[10] Mardiyanto, arief., dkk. 2017. "Rancang Bangun Sistem Monitoring Plan Pengontrol Proses Secara Realtime Pada Pembuatan Pupuk Organik". Politeknik Negeri Lhokseumawe.

[11] Handi, dkk. 2019. "Sistem Pemantauan Menggunakan Blynk dan Pengendalian Penyiraman Tanaman Jamur Dengan Metode Logika Fuzzy". Fakultas Ilmu Komputer, Universitas Brawijaya.

[12] Prayitno, dkk. "Sistem Monitoring Suhu, Kelembaban, dan Pengendali Penyiraman Tanaman Hidroponik menggunakan Blynk Android", Universitas Brawijaya, Indonesia, 2017.

[13] Harjanti, 2017. "Pupuk Organik dari Limbah Pabrik Gula Madukismo dengan Starter Mikrobia Pengurai Untuk Menambah Kandungan N, P, K”, Politeknik LPP, Yogyakarta.

[14] Supriatna, dkk. 2015. "Pendeteksi Suhu Dan Kelembaban Pada Proses Pembuatan Pupuk Organik". Politeknik Negeri Malang.

[15] Sinaga, Lidia Hana. 2019. "Monitoring Suhu dan Kelembaban Udara Menggunakan IoT (Internet of Things) Berbasis NodeMCU ESP8266". Universitas Sumatera Utara.

[16] Hapsari, Chrismalia; Wilujeng, Susi Agustina. 2011. Studi Emisi Karbondioksia (CO2) dan Metana (CH4) Dari Kegiatan Reduksi Sampah Diwilayah Surabaya Bagian Selatan. Teknik Lingkungan, ITS. Surabaya. 